\title{
TÜRK GÖLGE OYUNU KARAGÖZDE İSTANBUL HAYATI
}

\author{
Life in lstanbul in Karagöz, the Turkish Shadow Play
}

\author{
Dr. Dilaver DüZGüN*
}

\begin{abstract}
ÖZ
Türk seyirlik sanatları içinde önemli bi yere sahip bulunan karagöz oyunu, XVI yüzyıldan sonraki gelişme ve olgunlaşm sürecini İstanbul'da gerçekleştirmiştir. Burad son biçimini aldıktan sonra başka ülkelere yayılan oyun, yüzyıllar boyunca Türk eğlence kültürünün vazgeçilmez unsurları arasında yer almıștır. Osmanlı döneminde sarayda konaklarda, kahvehanelerde ve açık alanlard sergilenmiş, böylece geniş kitleler tarafindan kabul görmüștür.

Başta Evliya Çelebi ve çeşitli yabanc gezginlerin tanıklıkları olmak üzere çok sayıd eserin verdiği bilgiler, gölge oyununun istanbu hayatında etkin olduğunu ortaya koymaktadır ìstanbul halkının gündelik hayatının bir parças haline gelen karagöz oyununda ìstanbu hayatının farklı görünüşleri ağırlıklı bir biçimd karşımıza çıkar. Çeşitli gelenek, görenek ve hall inançlarının yanı sıra ístanbul'un farklı semtleri mesire yerleri, meslekler, sportif etkinlikler ve gündelik hayata ait olaylar Karagöz perdesind yansımasını bulmuştur. Bu yansıma, Türk gölge oyunu karagözün, özellikle Osmanlı dönem istanbul hayatının aydınlanmasınd başvurulacak bir kaynak haline gelmesin sağlamıştır.

Anahtar Sözcükler: Gölge oyunu, karagöz İstanbul, hayali (karagöz sanatçısı)
\end{abstract}

ABSTRACT

With a significant place in Turkish performance arts, karagöz shadow play went through its development and maturation process after the 16" century in Istanbul. The play, which spread to other countries after having taken its final shape here, has remained among the essential elements in Turkish entertainment culture for ages. It was performed in the court, palaces, coffee houses and outdoors in the Ottoman period and thus gained recognition among large audiences.

The information provided by many works in addition to the accounts of chiefly Evliya Çelebi and various foreign travelers reveal that shadow play was quite popular in lstanbul life. Various sights regarding the life in lstanbul appear predominantly in karagöz shadow play which became a part of the daily life of the people in lstanbul. Various parts of lstanbul, recreation spots, vocations, sports activities and daily events in addition to various customs and traditions and the beliefs of the people have been reflected on the karagöz screen. This reflection caused the Turkish shadow play Karagöz to become a source of reference in order to shed light upon particularly the life in Istanbul in the Ottoman period.

Keywords: Shadow play, karagöz, İstanbul, hayalî (Shadow play master)

\section{Giriş}

Türk eğlence hayatında en az 500 yıllık bir geçmişe sahip bulunan gölge oyununun Türkiye'de ilk kez ne zaman ortaya çıtığına dair tartı̧̧malar kesin biçimiyle sonuçlanmış değildir. Ancak, oyunun Türk damgasına kavuşması sürecinin i̇stanbul merkezli olduğu yadsınamaz bir gerçektir.

*Atatürk Üniversitesi Edebiyat Fakültesi Türk Dili ve Edebiyatı Bölümü Öğretim Üyesi. 
Bu çalışma, İstanbul'un Türk gölge oyunu üzerindeki etkisini araştırmayı amaçlamaktadır. Konunun ele alınması gereken iki boyutu söz konusudur: 1. Gölge oyununun icra mekânı olarak İstanbul, 2. Gölge oyunu metinlerinde İstanbul'un yansıması. Birinci problem ele alınırken istanbul hayatında gölge oyununun bıraktı̆̆ı etkiler ele alınmış, ikinci problemin açıklık kazanması için ise karagöz oyun metinlerine başvurulmuştur. Böyle bir araştırmanın sınırlarını zorlamaması ve özellikle ìstanbul vurgusunu dikkatlere sunması bakımından elimizde bulunan onlarca oyun metni içinden bir seçme yapılmış ve kâr-ı kadim olarak adlandırılan 28 oyun metni incelenmiştir. Tümü Hellmut Ritter tarafından yazıya geçirilen ve daha sonra Cevdet Kudret'in bir araya getirdiği 28 oyun şunlardır: Abdal Bekçi, Ağalık, Bahçe, Balık, Büyük Evlenme, Canbazlar, Cazular, Çeşme, Ferhad ile Şirin, Hamam, Kanlı Kavak, Kanlı Nigâr, Kayık, Kırgınlar, Mandıra, Meyhane, Orman, Ödüllü (Pehlivanlar), Salıncak, Sünnet, Şairlik, Tahir ile Zühre, Tahmis, Ters Evlenme, Tımarhane, Yalova Safası, Yazıcı.'

\section{Gölge Oyununun İcra Mekânı Olarak İstanbul}

Türk gölge oyununun kökeni ile ilgili bilgilerin bir kısmı efsane ve rivayetlerden, bir kısmı da tarihsel belgelerden oluşur. Cami inşaatı ile ilgili efsaneler çeşitlilik arz eder ve bunlar karagözün Türkiye'de ilk kez ortaya çıkışı konusunda mekân olarak Bursa civarını, zaman olarak Orhan Gazi veya Yıldırım Bayezit dönemini, yani XIV. yüzyılı gösterirler. ${ }^{2}$ Bu efsaneler arasında bir de oyunun mucidi olarak sunulan Şeyh Küşteri'nin bulunduğunu belirtmek gerekir.

Türk tiyatro tarihi araştırmalarının büyük ismi Metin And, konuyla ilgili kitap ve makalelerinde efsane ve rivayetleri, başta Evliya Çelebi olmak üzere yerli ve yabancı gezginlerin izlenimlerini ve diğer tarihsel belgeleri ayrıntılı bir biçimde inceleyerek gölge oyununun Yavuz Sultan Selim'in Mısır seferi dönüşünde İstanbul'a getirdiği sanatçılar tarafından Türkiye'ye taşındığı kanaatine ulaşır. ${ }^{3}$ And'ın bu görüşü kültür tarihi araştırmacıları arasında genel bir kabul görmekle birlikte sözlü rivayetlerin ortaya koyduğu soru işaretlerini bütünüyle ortadan kaldırmamıştır. Karagöz oyununun mukaddime bölümünde yer alan perde gazellerinde oyunun mucidi olarak sunulan ve kendisinden meslek piri sıfatıyla ve saygıyla bahsedilen Şeyh Küşteri'nin kimliğinin açıklığa kavuşturulması, bu konuda araştırmacılar için yeni ufuklar açacak niteliğe ve öneme sahiptir. Aynı şekilde, Orta Asya Türk topluluklarının eğlence, hatta kısmen inanç hayatında önemli bir yere sahip bulunan "çadır hayal"in mahiyeti hakkında doyurucu bilgilerin elde edilmesi de araştırmalara ciddi boyutlar kazandırabilecek niteliktedir.

Bu tartışmalar arasında ortaya çıkan gerçek şudur: 1517'den önce Türkiye'de gölge oyununun varlığını kanıtlamak güç olduğu kadar bu tarihten önce Türklerin böyle bir oyunla tanışmamış olduklarını iddia etmek de aceleci davranmaktan öte bir tutum

' Cevdet Kudret, Karagöz, 3 c., Bilgi Yay., Ankara 1968-1969-1970

${ }^{2}$ Saim Sakaoğlu, Türk Gölge Oyunu Karagöz, Akçağ Yay., Ankara 2003, s.36-39

${ }^{3}$ Metin And, Geleneksel Türk Tiyatrosu-Köylü ve Halk Tiyatrosu Gelenekleri, İnkılap Kitabevi Yay., İstanbul 1985, s. 275 
olmaz. Bu noktada İstanbul'u gölge oyununun doğuş yeri olarak kabul etmek ne kadar tutarlı olur? Bu soruyu Sabri Esat Siyavuşgil şöyle yanıtlar: "Karagöz mevzuubahs ise, evet; hayal mevzuubahs ise, hayır."

İstanbul'un, Türk gölge oyununun ilk kez ortaya çıktığı yer olup olmadığı tartışmalı ise de oyunun gelişme ve olgunlaşma sürecini bu kentte tamamladığı kesin bir gerçektir. XVl. yüzyılın ünlü şeyhülislamı Ebussuud Efendi'nin fetvalarına girmesi, ${ }^{5}$ onun, imparatorluk başkenti ìstanbul'da toplumun bütün kesimleri tarafindan bilinen bir oyun olduğunu ortaya koyar. 1582 şenliğini anlatan Surname-i Humayun'da oyunun tasvir ediliş biçimi de yine gölge oyununun XVl. yüzyıl ìstanbul eğlence hayatında önemli bir boyut kazandığına işaret eder. ${ }^{6}$ Hatta XVl. yüzyıla ait bir belgede "cemaat-i hayal-i zılciyan" başlı̆g altında oyuncu takımlarının adlarının verilmesi ve takımların kaçar kişiden oluştuklarının belirtilmesi, bu oyuncu gruplarının istanbul eğlence hayatında etkin olduklarını gösterir. ${ }^{7}$ XVIl. yüzyılın ünlü seyyahı Evliya Çelebi de döneminin meslek grupları arasında "hayal-i zılciyan" ve "hayal-i zıll-i tasvirciyan"1 anar. Bütün bu belgeler, gölge oyununun XVI ve XVIl. yüzyıllarda ístanbul'da gelişimini tamamladı̆̆ görüşünü desteklemektedir.

İstanbul'da biçimlenen ve Türk milli kültürünün bir parçası haline gelen gölge oyunu, gerek saray çevresinde ve aydınlar arasında, gerekse halk arasında yaygın bir oyun olma özelliği kazanmıştır. İstanbul'un, uzun bir süre imparatorluk başkenti ve daima bir sanat şehri oluşu, onun gölge oyunu ile bütünleşme sürecini hızlandırmış ve kalıcı hale gelmesini sağlamıştır. Bu süreçte sanatçı ve izleyici gruplarının birbirlerini etkilediği, hatta oyunun başka sanat kollarıyla etkileşime girdiği görülür. İstanbul kenti, sanatçısını yetiştirmiş, oyunlara kendi bünyesinden malzeme vermiş, sergilenme zeminlerini oluşturmuştur. "Karagöz oyunlarını oynatan hayaliler, bulundukları siyasal, kültürel çevreden etkilenen, bu etkiyle eserlerini ortaya koyan ve eserleriyle o çevreyi etkileyen sanatçılardır. Bu açıdan karagöz oyunlarını sahneye konuldukları dönem Osmanlı toplumunun gerçeklerinden bağımsız düşünebilmenin imkânı yoktur." ${ }^{9}$ Hatta

${ }^{4}$ Sabri Esat Siyavuşgil, İstanbulda Karagöz ve Karagözde istanbul, Eminönü Halkevi Yay., ìstanbul 1938, s. 3-4

5 Ebussuud Efendi'nin fetvaları arasında doğrudan gölge oyunu ile ilgili üç fetva tespit edilebilmiştir. Bunlardan biri şöyledir: MES'ELE: Hayal-i zıl için ba'zı ehl-i basiret "hayal-i zıllın hakikat ilminden nasibini alan için en büyük iret olduğunu gördüm. Kişiler ve silüetler geçip yok oluyor ve hızlı bir şekilde ortadan kayboluyor. Oysa muharrik (gölge oyunu ustası) yerinde kalıyor" demiştir. Hem "mahal-i ibrettir" deyu buyurduğu vaki midir? ELCEVAP: Vakidir. Erbab-i besair-i selimeye ibret-i acibedir. (Mehmet Ertuğrul Düzdağ, Şeyhülislam Ebussuud Efendi Fetvaları lşı̆̆ında 16. Asır Türk Hayatı, Enderun Kitabevi Yay., İstanbul 1972, s. 201)

${ }^{6}$ Metin And, a.g.e., s. 279

${ }^{7}$ And, a.g.e., s. 281

${ }^{8}$ Evliya Çelebi b. Derviş Muhammet Zılli, Evliya Çelebi Seyahatnamesi, c.l, (Haz. Orhan Şaik Gökyay), Yapı Kredi Yay., İstanbul 1996, s. 338

${ }^{9}$ Aynur Koçak, "Karagöz Oyunlarındaki Tuzsuz Deli Bekir Tipi Üzerinde Bazı Değerlendirmeler", Milli Folklor, sayı: 56, Kış 2002, s. 121-129 
oyunların sergilendiği ortamlar yeni sanat eserleri vücuda getirilmesine de zemin hazırlamıştır. Şehzadelerin doğumu veya evlenmeleri, padişahın tahta çıkışı, bir yabancı devlet adamının ìstanbul'a gelişi gibi gerekçelerle düzenlenen şenlikler, surname adlı manzum veya mensur eserlerin ortaya çıkmasını sağlamıştır. Bu eserler karagözün saray tarafından organize edilen bu tür şenliklerde de yer aldığını gösteriyor. ${ }^{10}$

XIX. yüzyılda İstanbul'da karagöz oyunlarının sunulduğu mekânların çokluğu dikkat çekiyor. Bunların bir kısmı sadece karagöz gösterimleri için düzenlenen yerler olduğu gibi bazıları da gölge oyunu sanatçılarına kapılarını açan başka mekânlardı. Özellikle kahvehaneler, diğer sanatsal etkinliklerin yanı sıra karagöz gösterimlerine de ev sahipliği yapıyorlardı. Ayrıca İstanbul'un çeşitli semtlerindeki hanlarda ve bahçelerde de karagöz oynatıldığı biliniyor. Metin And, çeşitli kaynaklardan tespit ettiği bu mekânların adlarına eserinde yer vermiştir."

\section{Gölge Oyunu Metinlerinde İstanbul Hayatı}

Türk gölge oyunu geleneğinde ve oyun metinlerinde ìstanbul, çeşitli görünüşleriyle karşımıza çıkar. Yukarıda belirtildiği gibi bu çalışmada incelediğimiz oyun metinlerinin kâr-ı kadim olmasına özen gösterilmiştir. Kâr-ı kadim oyunların XVl, XVII. yüzyıllarda ortaya konulduğu ve o dönemlerde toplumun gündeminde olan konuları ele aldıkları biliniyor. Ancak, her sanat dalında olduğu gibi gölge oyununda da değişen şartların farklı bakış açılarının gelişmesine neden olması ve sunulduğu dönemi çeşitli açılardan yansıtması kaçınılmazdır. Bu nedenle elimizdeki kâr-ı kadim oyun metinleri, konularını önceki yüzyıllardan almakla birlikte büyük ölçüde, tespit edildikleri ve yazıya geçirildikleri dönemin, yani XIX. yüzyıl sonları ve XX. yüzyıl başlarının yaşam tarzını yansıtırlar. Oyunlarda şimendifer, sinematograf, tiyatro, itfaiye, Şirket-i Hayriye gibi XIX. yüzyılda ortaya çıkan araç, sanat etkinliği ve kurum adlarına yer verilmesi, bunların XIX. yüzyıl İstanbul hayatından birçok unsuru aldığını göstermektedir.

Oyunlarda İstanbul hayatı karagöz perdesinin imkânları ölçüsünde dikkatlere sunulur. Burada, bir makalenin şartlarını zorlamayacak biçimde, öne çıkan bazı özellikler ele alınacaktır.

\subsection{Yer adları}

İncelediğimiz karagöz oyun metinlerinde en çok dikkat çeken husus, yer adlarına sıkça rastlanmasıdır. Bunların bir kısmı İstanbul dışındaki çeşitli il ve ilçe gibi yerleşim merkezleridir. Yer adlarının çoğu ìstanbul'la ilgilidir. Oyunlarda ístanbul'dan ìstanbul diye bahsedildiği gibi Asitane-i Aliyye, Dar-ı Hilafet-i Aliyye, Der-Aliyye gibi adlarla da

10 Örneğin, Güranlı Hızır olarak tanınan Hızri, 1252 (1836) yılında ll. Mahmut'un şehzadeleri Abdülmecid ve Abdülaziz için düzenlenen düğünü anlattığı surnamesinde gölge oyununundan şöyle bahseder:

Kimi oldı perde-i lu'b-ı hayale perdegi

Bezle ile iyledi halkı ser-a-ser dil-güşa

(Mehmet Arslan, Türk Edebiyatında Manzum Surnameler (Osmanlı Saray Dügüüleri ve Şenlikleri), Atatürk Kültür Merkezi Başkanlığı Yay., Ankara 1999, s. 275, 787)

" And, a.g.e., s. 332-333 
bahsedilmektedir. Oyunlarda ìstanbul'un birçok semti, mahallesi, sokağı çeşitli vesilelerle gündeme gelir. Bunlardan tespit edebildiğimiz 105 yer adışunlardır:

Akbıyık, Aksaray, Anadoluhisarı, Anadolukavağı, Arnavutköyü, Atpazarı, Ayvansaray, Balat, Balık Pazarı, Bayrampaşa, Beşiktaş, Beyazıt, Beykoz, Beylerbeyi, Beyoğlu, Bitpazarı, Boğaziçi, Boyacıköyü, Büyükçekmece, Büyükdere, Cibali, Cihangir, Çakmakçılar yokuşu, Çamlıca, Çarşamba Pazarı, Çavuşbaşı, Çemberlitaş, Çene, Çengelköyü, Çukurçeşme, Direklerarası, Dörtkardeşler, Edirnekapısı, Erenköyü, Esirpazarı, Eyüp, Fatih, Fener, Feriköyü, Fındıklı, Firuzağa, Galata, Göksu, Göztepe, Güzelhisar, Halıcıoğlu, Harem, Haseki, Hasköy, Havuzbaşı, Haydarpaşa, İncirli Kuyu, İstinye, Kabataş, Kadıköyü, Kadırga, Kağıthane, Kandilli, Kanlıca, Karagümrük, Kasımpaşa, Koska, Kumkapı, Kuruçeşme, Kuzguncuk, Küçükçekmece, Küçüksu, Lutfupaşa, Maltepe, Merdivenköyü, Mirgün, Odunkapısı, Parmakkapı, Pendik, Rumelihisarı, Salacak, Salıpazarı, Samatya, Saraçhane, Sarayburnu, Sarıgüzel, Sarıyer, Selamsız, Silahtar, Silivri kapısı, Sirkeci, Sulukule, Tahtakale, Taksim, Tarabya, Tavukpazarı, Tepebaşı, Terlikçi Sokağı, Tophane, Toptaşı, Unkapanı, Üsküdar, Vefa, Yağkapanı, Yahnikapan Sokağı, Yedikardeşler, Yenikapı, Yeniköy, Yenimahalle, Zeyrek yokuşu. Bunlardan Fatih semtinin adı iki kez Sultan Mehmet olarak geçer.

Ayrıca Harem iskelesi, Karacaahmet Mezarlığı, Kız Kulesi, kimi kez Çarsu-yı Kebir olarak sunulan Kapalıçarşı, Kıztaşı, Mısır Çarşısı, Simkaş Hanı, gibi yapılar da söz konusu edilir.

\section{2. İnançlar, gelenek ve görenekler}

Karagöz oyunlarında ìstanbul halkının çeşitli konulardaki inançları, gelenek ve görenekleri dikkatlere sunulur. Bu açıdan bakıldığında her oyunun gelenek, adet, inanç veya gündelik hayatla ilgili bir problemi ele aldığı anlaşılır. Örneğin Büyük Evlenme'de İstanbul'un evlenme gelenek ve adetleri, Şairlik'te saz şairleri ve müşaare gelenekleri gündeme getirilir. Oyunların gerek muhavere, gerekse fasıl bölümlerinde yer alan gündelik hayatla ilgili birçok uygulamanın söz konusu aldığı görülür. Abdal Bekçi oyununun başındaki muhaverede hanımların hamam sefası çeşitli yönleriyle tasvir edilir; hamama müşteriler tarafından turşu götürülmesi, ana kadın adlı görevlinin müşterileri karşılaması, emzikli kadının turşu istemesi gibi ayrıntılar aktarılır. Bu arada çeşitli hamam eşyaları, araç-gereçleri tanıtılır: peştamal, silecek, küçük havlu, baş havlusu, nalın, hamam tası, endam aynası, el aynası, baş tarağı, elbise fırçası. Ayrıca, farklı oyunlarda çeşitli hamam adları geçer. Çukur Çeşme Hamamı, Tophane Hamamı, Kasavat Hamamı, Kurubalık Hamamı ve Şifa Hamamı, bunlardan birkaçıdır.

Ramazan ayıyla ilgili olarak oruç, iftar topu, sahur, mahya gibi ibadet, adet ve uygulamaların söz konusu olduğu karagöz oyunlarında idgâh diye adlandırılan bayram yerinden de sıkça söz edilir. Dolap adı verilen salıncak, idgâhın ilk akla gelen eğlence aracıdır.

Başta görücülük olmak üzere çeşitli düğün adetleri, büyücülük, cincilik, cin çarpması, falcılık gibi her dönemde varlığını koruyan halk inanmalarının istanbul'daki 
görünüşü hayal perdesine yansıtılır. Komşuluk ilişkileri, aile hayatı, meslek merasimleri, ticaret, bereket, kısmet gibi konulardaki inançlar farklı açılardan dikkatlere sunulur.

\subsection{Meslekler ve çeşitli iş kolları}

Oyunların sahnelendiği dönemlerde ìstanbul'da etkinliğini sürdüren çok sayıda meslek, zanaat, sanat ve iş kolları, çeşitli vesilelerle karagöz perdesinde yer bulur. Kâr-ı kadim oyunlardan tespit ettiğimiz 78 iş ve meslek adı şunlardır:

Ahçı, aktar, ana kadın, astarcı, aşureci, ayvaz, bahçıvan, bakıcı, bakkal, balıkçı, bekçi, berber, bezirgan, börekçi, büyücü, camcı, cambaz, curcunabaz, çamaşırcı, çengi, çulha, deveci, dondurmacı, dülger, ebe, eczacı, ekmekçi, enfiyeci, eşekçi, fundacı, gazinocu, gemici, gözlükçü, hamal, hamamcı, hekim, işkembeci kaşıkçı, kadayıfçı, kahveci, kahya, kalafatçı, kasap, kayıkçı, keserci, kilimci, köçek, kuyumcu, külhancı, lağımcı, manav, manifaturacı, maşacı, meddah, meyhaneci, muhallebici, musikişinas, muslukçu, mutaf, nakkaş, natır, nöker, oyuncakçı, örücü, palyaço, rençber, saatçi, sazcı, semerci, sünnetçi, şatır, şekerci, şerbetçi, terzi, turşucu, yazıcı, yorgancı, zerzevatçı.

\subsection{Beslenme kültürü}

İstanbul halkının beslenme kültürü ilgili ayrıntıları da oyun metinlerinde bulmak mümkündür. Başta normal ekmek ve francala adı verilen, özel bir undan yapılmış olan ekmek olmak üzere çorba, işkembe çorbası, balık ızgarası, fasulye yahnisi, keşkek, kıyma, kuru fasulye, musakka, pilav, taskebabı, tatar böreği, yahni gibi yemek adları geçer. Bu yemeklerin yapımında kullanılan soğan, sarımsak, tuz, biber, salça, gibi yemek malzemeleri de sık sık gündeme gelir. Armut, biber, börülce, dereotu, domates, enginar, erik, fasulye, havlıcan, hindistan cevizi, ıspanak, kabak, karanfil, karpuz, kayısı, kereviz, lahana, limon, maydanoz, nane, nar, nohut, patlıcan, pırasa, portakal, salatalık, sinameki, şalgam, şeftali, tere otu, turp, üzüm, zerdali, gibi meyve, sebze ve baharatlar yeri geldiğinde söz konusu edilir. Et, balık pastırma ve sucuk da yemeklikler arasında anılır. Helva, pekmez, peynir, zeytin gibi kahvaltılık yiyeceklerden bahsedilir. Aşure, ballı lokma, ekmek kadayıfı, güllaç baklavası, kadayıf, kurabiye, muhallebi, pasta, revani, sütlaç, dilberdudağı, keşkülüfukara, hanımparmağı, hanımgöbeği gibi tatlılar tanıtılır. Karagöz oyunlarında adı geçen içecekler de şunlardır: kahve, nargile, adaçayı, ıhlamur, ağaç hatmisi, mürver çiçeği, limonata.

\section{5. Çeşitli sanatsal etkinlikler, eğlence hayatı, oyunlar}

İstanbul'da ortaya konulan çok sayıda sanatsal gösteri karagöz oyunlarında gündeme gelir. Hatta bunların bir kısmı oyun içinde oyun yöntemiyle seyirciye sunulur. Perdede ayrıca bir karagöz perdesinin kurulması ve gölge oyunu gösteriminin sunulması, meddah ve ortaoyunu, köçek, çengi, curcuna gösterilerine yer verilmesi gibi. Ayrıca çeşitli rakslar, palyaço, kemancı, defçi, davulcu gibi sanatçıların perdede görülmesi sıkça karşılaşılan bir durumdur. Bu arada çeşitli şarkıların okunması, mani ve bilmecelerin ortaya konulması, hikâye anlatılması, aşık fasıllarının sunulması ve zaman zaman bu fasılların gerçekleştiği mekânlardan, adam aman sözleriyle başlayan cinaslı manilerin sıkça okunduğu tulumbacı kahvelerinden, hokkabazlıktan, tiyatro 
salonlarından söz edilmesi, i̇stanbul'un eğlence hayatıyla ilgili birçok ayrıntının karagöz perdesinde yer bulduğunu gösteriyor.

Oyunlarda sarhoş ve kabadayıların uğrak yeri olan meyhanelere de rastlanır. Avram Papi'nin Meyhanesi, Kafesli Meyhane gibi mekân adları geçer. Ayrıca aşüfte kadınların eğlenceleri arasında içki alemlerine de yer verilir. Yabancı erkeklerle evlilik dışı ilişki kuran Kanlı Nigâr gibi kadınların evlerinde bulunan içki çeşitleri abartıı bir biçimde sunulur. Birer batakhane görünümünde olan bu evlerde ve meyhanelerde bulunan içki adları şunladır: rakı, şarap, konyak, amer, viski, mastika, absent, iksir, venso, kakao, bermut, oltom, şampanya, bordo, pismark, rom. Meze türleri de şöyle sıralanır: balık tavası, midye dolması, lüfer ızgara, sığır dili, havyar ezmesi, turşu balığı (salamura balık), elma, armut, üzüm, kavun, karpuz, incir. Ayrıca karagöz perdesinin bazı tipleri afyon kullanırlar. Özellikle Tiryaki, bir afyon bağımlısıdır ve aksesuarı arasında bir de enfiye kutusu vardır.

Karagöz oyunlarında çeşitli oyunların adları bazen oynanış biçimleriyle ilgili ayrıntılarla birlikte dikkatlere sunulur. Açık havada oynanan turnike, arkalıç, köşe kapmaca, ecelbeşiği, tahtaravalli gibi oyunların yanı sıra tavla, domino, satranç gibi masa üstü oyunlarından da bahsedilir. Bir kısmı günümüzde bilinmeyen çeşitli oyun adları şunlardır: peçiç, yüzük, paket oyunu, laco, balık kaçtı, tramvay, körebe, masana.

\subsection{Giyim kuşam ve süslenme}

Türk gölge oyununda perdeye gelen tiplerin kıyafetleri kadar konuşmalar arasında geçen giyim kuşamla ilgili tasvirler de döneminin İstanbul hayatını bir başka yönüyle dikkatlere sunar. Özellikle kadın giyimi, süslenme ve makyajla ilgili önemli ipuçları ortaya konulur. Kadınların kullandığı ziynet eşyaları ve takılar arasında altın, inci, elmas, yakut, zümrüt gibi mücevherler; hotoz, altın saat, akarsu diye adlandırılan gerdanlık, yıldız iğnesi, broş, yüzük, küpe, bilezik ve beşibiryerde bulunur. Hatta bunların taşlı yüzük, tek taşlı yüzük, dut-küpe gibi farklı türlerinden, akmakçılar simidi olarak adlandırılan özel bir hotoz biçiminden bahsedilir. Makyaj gereçleri olarak da tuvalet takımı, pudra kutusu, allık, düzgün, rastık, pudra ve sürme adları geçer.

Tahir ile Zühre oyununda Zühre'nin babasının Karagöz'e söylediği şu sözler, dönemin i̇stanbul hayatında özellikle varlıklı ve zevk sahibi aileler arasında geçerli olan kadın makyajı, giyim kuşamı, edası ve gönül ilişkileri hakkında fikir verebilecek niteliktedir:

Hanıma söyle "efendi şükûfe-zarda teşrifine muntazır" de. Serine kelle-puşunu örtsün de gelsin, anber geysularını tarasın da gelsin, Ebrularına rastık çeksin de gelsin, müjgânına sürme çeksin de gelsin, ruhsarına zülüflerini döksün de gelsin, sib-i zenehdanını örtsün de gelsin, vech-i zibasını örtsün de gelsin, elbise-i fahiresini giysin de gelsin, yeşil camelerini giysin de gelsin, gûşuna mengûşunu taksın da gelsin, altın bileziğini koluna, tek taşlı yüzüğünü parmağına taksın da gelsin, sarı kemerini beline, yelpazeyi eline alsın da gelsin, yaşmaklarını giysin de gelsin, çeşm-i mahmurlarını süzerek, etraf u eknafi gezerek gelsin, reftar ile naz ederek gelsin, bin naz ile işvebazlıkla 
gelsin, servi gibi hıram eyliyerek gelsin, vücud-ı nazikanelerini incitmiyerek gelsin, kalb ferahnak olup safalarla meserretle gelsin. ${ }^{12}$

\subsection{Musiki}

Karagöz oyunlarında musiki ayrı bir yer tutar. Tiplerin perdeye yansıttıkları musiki atmosferinin yanı sıra konuşmalarda geçen müzik terimleri, İstanbul musiki hayatının oyunlara çok etkili bir biçimde yansıdığını gösterir. Bir yandan halk çalgıları, diğer yandan entelektüel çevrelerde varlığını koruyan musiki zevki karagöz perdesinde ayrıntılarıyla sunulur. Saz, davul, zurna, def, dümbelek, ud, keman gibi enstrüman adlarına, âşık fasılları, semai, kerem ve garip havalarına değinilir. Ferhat ile Şirin oyununun muhavere bölümünde Hacivat, Karagöz'le konuşurken şu makam adlarını sıralar: mısri, halebi, bağdadi, trablusşami, leyli, yürük beste, aksak semai, türk aksağı, nev-zemin, nim-devir, râst, neva, nihavend, rahatül-ervah, ısfahan, hisar-buselik, evc-ârâ, çargâh, ferahnâk, neva-yi tatar, karabatak, saba, beste-nigâr, hüzam, nev-eser, hüseynîaşiran, nühüft, çifte-düyek, devr-i revan, zencir, devr-i kebir, segâh, sabâ, muhayyersünbüle, acem-kürdi, neva-yi kürdi, araban, tarz-1 cedid, şevk-aver, dilkeş-haveran, sûzinâk, müstear, mahur. ${ }^{3}$

\section{8. Tipler}

Türk gölge oyununun tipleri de İstanbul'da yaşayan farklı etnik ve dinsel kökenlere, kültürel ve sosyal çevrelere mensup insanları temsil etmektedir. Bunlardan her birinin fiziksel görünümleri, ruhsal durumları, giyim kuşamları ve davranış biçimleri, ayrı ve kapsamlı bir araştırmanın konusu olabilecek boyuttadır. Karagöz oyununun kalabalık şahıs kadrosu dikkate alındığında oyunların sergilendiği döneme ait İstanbul'un insan tipi üzerine ciddi ayrıntıların ortaya çıkacağı muhakkaktır.

\subsection{Diğer unsurlar}

Lale devri adı verilen dönemiyle ünlü İstanbul'un her dönemde zengin bir çiçek kültürünü bünyesinde barındırdığı bilinir. İstanbul'da yetişen ve kibar konaklarını, bahçeleri süsleyen çiçeklerden bir kısmı gölge oyunu perdesinde de mevcuttur. Fesleğen, şebboy, nergis, yasemin, karanfil, gül, sümbül, menekşe, şebboy, hatmi çiçeği, gelincik çiçeği, menekşe gibi çiçeklerden, salkım ağaçlarından, karanfil saksılarından bahsedilir.

Karagöz oyunlarında Osmanlı eğitim sistemi içinde okutulan belli başlı eserler ve müfredat hakkında bazı bilgilere de rastlamak mümkündür. Özellikle kendi birikimini vurgulamak üzere Hacivat'in Arapça, Farsçadan, I'rab ve i'lalden, uzun yıllar Osmanlı medreselerinde okutulan Sarf, Emsile, Bina, Maksud, İzzi, Merah, Avamil, Kâfiye, İzhar, Mantık gibi kitaplardan bahsettiği görülür. Hacivat'ın adını andığı diğer eserler şunlardır: Risale-i Ahlak, Medhal-i Kavaid, Hikâye-i Müntehabe, Talim-i Farisi, Kavaid-i Farisi, Tuhfe-i Vehbi, Sübha-i Sıbyan, Pend-i Attar, Gülistan, Hafız Divanı.

${ }^{12}$ Cevdet Kudret, Karagöz, c. 2, Bilgi Yay., Ankara 1969, s. 220-222

${ }^{13}$ Cevdet Kudret, a.g.e., s. 108-111 
Bunlardan başka, kişi adları, lakaplar, İstanbul'un ünlü simaları, dükkân, apartman, yalı ve köşkleri, ünlü işyerleri, mesire yerleri, resmi kuruluşlar, sokak satıcıları, ev dekorasyonu ve eşyaları, çeşitli işyerlerinde kullanılan araç gereçler, ölçüler, para birimi, deyimler, atasözleri, çeşitli denizcilik ve balıkçılık kavramları, hastalık adları ve gündelik hayatla ilgili daha başka ayrıntılar karagöz perdesinde seyircilere sunulur.

\section{Sonuç}

Gelişmesini imparatorluk başkenti İstanbul'da tamamlayan ve böylece Türk milli zevkiyle şekillenen karagöz oyunu bir yandan ìstanbul'un eğlence hayatına farklı görünümler kazandırırken bir yandan da kendi bünyesine ìstanbul hayatından çeşitli unsurları almıştır. Oyunlarda İstanbul'un çeşitli semt, mahalle, sokak, cadde adları; cami, hamam, köşk, iskele, kule gibi yapılar çokça anılır. Birtakım gelenek ve görenekler, adetler ve inançlar, oyunların ortaya konulduğu dönemin i̇stanbul hayatı hakkında önemli ipuçları verecek niteliktedir. Oyunlar, İstanbul halkının dili, eğitimi, giyim kuşamı, beslenme kültürü hakkında ayrıntılı bilgilerin yanı sıra ístanbul'daki sanatsal etkinlikler, eğlence yerleri ve biçimleri, oyunlar, müzik dünyası, edebiyat ve sanat atmosferi ile ilgili zengin bir tablo sunar. Bu yönüyle karagöz oyunları kendi şartları içinde küçük bir İstanbul ansiklopedisi niteliğindedir.

\section{KAYNAKÇA}

AND, Metin, Geleneksel Türk Tiyatrosu-Köylü ve Halk Tiyatrosu Gelenekleri, İnkılap Kitabevi Yay., İstanbul 1985.

ARSLAN, Mehmet, Türk Edebiyatında Manzum Surnameler (Osmanlı Saray Dügünleri ve Şenlikleri), Atatürk Kültür Merkezi Bşk. Yay., Ankara 1999.

Cevdet Kudret, Karagöz, 3 c., Bilgi Yay., Ankara 1968-1969-1970.

DüZDAĞ, Mehmet Ertuğrul, Şeyhülislam Ebussuud Efendi Fetvaları Işığında 16. Asır Türk Hayatı, Enderun Kitabevi Yay., İstanbul 1972.

Evliya Çelebi b. Derviş Muhammet Zılli, Evliya Çelebi Seyahatnamesi, c.l, (Haz. Orhan Şaik Gökyay), Yapı Kredi Yay., İstanbul 1996.

KOÇAK, Aynur, "Karagöz Oyunlarındaki Tuzsuz Deli Bekir Tipi Üzerinde Bazı Değerlendirmeler”, Milli Folklor, sayı: 56, Kış 2002, s. 121-129.

SAKAOĞLU, Saim, Türk Gölge Oyunu Karagöz, Akçağ Yay., Ankara 2003.

SiYAVUŞGil, Sabri Esat, İstanbulda Karagöz ve Karagözde istanbul, Eminönü Halkevi Yay., İstanbul 1938.

SiYAVUŞGil, Sabri Esat, Karagöz Psiko-sosyolojik Bir Deneme, Maarif Vekilliği Yay., İstanbul 1941.

ÜNGÖR, Etem Ruhi, Karagöz Musikisi, Kültür Bakanlığı Yay., Ankara 1989. 